\title{
Níveis de Lisina para Leitoas Selecionadas Geneticamente para Deposição de Carne Magra na Carcaça, dos 30 aos 60 kg1
}

\section{Dalton de Oliveira Fontes ${ }^{2}$, Juarez Lopes Donzele ${ }^{3}$, Rita Flávia Miranda de Oliveira $^{3}$, Darci Clementino Lopes $^{3}$, Aloízio Soares Ferreira ${ }^{3}$, Francisco Carlos de Oliveira Silva ${ }^{4}$}

RESUMO - Foram utilizadas 50 leitoas híbridas, com alto potencial genético para deposição de carne magra na carcaça e pesos inicial e final de 30,0 $\pm 0,45$ e 59,9 $\pm 2,53 \mathrm{~kg}$, respectivamente, para avaliar diferentes níveis de lisina. O delineamento experimental foi o de blocos ao acaso, com cinco tratamentos, cinco repetições e dois animais por unidade experimental. Os tratamentos corresponderam a uma ração basal com 17,5\% de proteína bruta, suplementada com cinco níveis de L-lisina $\mathrm{HCl}$, resultando em rações com 0,80; 0,90; 1,00; 1,10; e $1,20 \%$ de lisina total. Não se observou efeito dos tratamentos sobre o ganho de peso diário e a concentração de uréia no soro sangüíneo dos animais, entretanto, o consumo de ração e o consumo de lisina diário aumentaram linearmente. Houve efeito quadrático dos níveis de lisina sobre a conversão alimentar, que melhorou até o nível de $1,16 \%$ de lisina total (0,347\%/Mcal de ED) ou 1,05\% de lisina digestível (0,315\%/Mcal de ED), correspondendo a um consumo estimado de lisina total e digestível de 21,8 e 19,7 g/dia, respectivamente. Não se observou efeito dos tratamentos sobre a porcentagem de proteína da carcaça, porém a de água diminuiu de maneira linear. Houve efeito quadrático dos tratamentos sobre a porcentagem e taxa de deposição de gordura na carcaça, que diminuíram até o nível de 1,09 e 1,12\% de lisina, respectivamente, e sobre a taxa de deposição de proteína, que foi máxima no nível de 1,04\% de lisina. Concluiu-se que leitoas selecionadas geneticamente para deposição de carne magra na carcaça, dos 30 aos $60 \mathrm{~kg}$, exigem 1,16\% de lisina total ou 1,05\% de lisina digestível verdadeira, para melhor desempenho, correspondendo a um consumo diário de lisina total e digestível de 21,77 e 19,72 g, respectivamente. O nível de 1,04\% de lisina total ou $0,93 \%$ de lisina digestível proporciona a melhor taxa de deposição de proteína na carcaça.

Palavras-chave: carcaça, exigência, fase de crescimento, genótipo, lisina, uréia

\section{Levels of Lysine for Gilts with High Genetic Potential for Lean Gain from 30 to $60 \mathrm{~kg}$}

ABSTRACT - Fifty hybrid gilts, with high genetic potential for lean gain and initial and final average weight of $30.0 \pm 0.45$ and $59.9 \pm 2.53 \mathrm{~kg}$, respectively, were used in an experiment to evaluate diet with different levels of lysine. An experimental design of randomized blocks, with five treatments, five replicates and two animals per experimental unit, was used. The treatments corresponded to a basal diet with $17.5 \%$ crude protein, supplemented with five levels of HCl-L-lysine, resulting in diets with $0.80,0.90,1.00,1.10$, and $1.20 \%$ of total lysine. There were no effects of treatments on daily weight gain and serum urea concentration, however, daily feed intake and daily lysine intake increased linearly with the dietary lysine level. There was a quadratic effect of lysine levels on feed:gain ratio, that increased up to the total lysine level of $1.16 \%(0.347 \% / \mathrm{Mcal}$ of DE) or $1.05 \%(0.315 \% / \mathrm{Mcal}$ of DE) of digestible lysine, corresponding to the total and digestible lysine intake of 21.8 and $19.7 \mathrm{~g} /$ day, respectively. There was no effect of treatments on protein percentage, however, the water percentage in carcass linearly decreased. There was quadratic effect of treatments on fat percentage and fat deposition rate in carcass, that decreased up to the lysine level of 1.09 and $1.12 \%$, respectively. The protein deposition rate improved quadraticly up to the level of lysine of $1.04 \%$. It was concluded that gilts with high genetic potential for lean gain, from 30 to $60 \mathrm{~kg}$ require $1.16 \%$ of total lysine or $1.05 \%$ ( $0.315 \% /$ Mcal of DE) of true digestible lysine, corresponding to total and digestible lysine intake of 21.8 and $19.72 \mathrm{~g} /$ day, respectively, for maximal performance. The level of total lysine of $1.04 \%$ or $0,93 \%$ of digestible lysine proportioned the best protein deposition rate.

Key Words: carcass, genotype, growing phase, lysine, requirement, urea

\section{Introdução}

A crescente preocupação com a saúde tem aumentado a preferência dos consumidores por carnes mais magras, desafiando toda a cadeia produtiva suinícola a produzir animais com maior taxa de tecido magro.
Estudando a evolução do percentual médio de carne magra nas carcaças de suínos em frigoríficos de Santa Catarina, Fávero (2000) observou que na década de 80 a porcentagem de carne magra era de aproximadamente $47 \%$, enquanto em 1999, esse percentual já estava entre 52,5 e $56,6 \%$. A porcentagem de carne magra aumentou $8,7 \%$ nessa déca-

\footnotetext{
1 Parte do trabalho de tese de Doutorado do primeiro autor - Projeto financiado pela FAPEMIG.

2 Professor da Escola de Veterinária da UFMG (dalton@vet.ufmg.br).

3 Professor do Departamento de Zootecnia da UFV.

${ }^{4}$ Pesquisador da Empresa de Pesquisa Agropecuária de Minas Gerais - EPAMIG.
} 
da, enquanto, na década seguinte, esse aumento foi de aproximadamente $15 \%$.

Segundo Close (1994), existem grandes diferenças na habilidade dos animais para crescimento e para conversão eficiente dos nutrientes em ganho de carcaça. O crescimento representa principalmente deposição de carne e de gordura no corpo e, em termos de eficiência de utilização do alimento, visa otimizar o ganho de carne e minimizar o ganho de gordura. Todavia, as necessidades de nutrientes para depositar carne e gordura são muito diferentes em termos de energia, proteína e aminoácidos.

Por sua vez, Bikker \& Bosch (1996) comentam que existem razões para desenvolver estratégias de alimentação que garantam ótima utilização dos alimentos para a produção de carne magra. Segundo os autores, a produção de tecido magro, em sua maioria constituído de proteína e água, é mais eficiente que a produção de gordura pelo animal, podendo haver redução dos custos de alimentação e, conseqüentemente, da produção de suínos.

Diversos trabalhos (Stahly et al., 1991; Nugent et al. 1994) têm demonstrado que suínos selecionados geneticamente para deposição de carne magra apresentam exigências nutricionais diferenciadas de outros grupos genéticos.

Dessa forma, o estabelecimento de estratégias de alimentação específicas tornou-se uma preocupação, pois, nos últimos anos, tem-se observado a introdução de diferentes grupos genéticos nos sistemas de produção de suínos de todo mundo.

Objetivou-se, com este trabalho, avaliar o efeito de níveis de lisina sobre desempenho, nível de uréia no soro sangüíneo, composição e taxas de deposição de gordura e proteína na carcaça de leitoas selecionadas geneticamente para deposição de carne magra, dos 30 aos $60 \mathrm{~kg}$.

\section{Material e Métodos}

O experimento foi conduzido no Setor de Suinocultura do Departamento de Zootecnia da Universidade Federal de Viçosa, utilizando-se 50 leitoas híbridas (irmãs do AGPIC 419), com peso inicial de $30,0 \pm 0,45 \mathrm{~kg}$, distribuídas em delineamento experimental de blocos ao acaso, com cinco tratamentos (níveis de lisina na ração), cinco repetições e dois animais por unidade experimental. Os blocos foram formados no tempo, cada um com duração média de $32,8 \pm 0,98$ dias. O peso inicial e o parentesco das leitoas foram usados como critério para distribuição dos animais dentro de cada bloco.

Os animais foram alojados em baias com comedouros semi-automáticos e bebedouros tipo chupeta, em galpão de alvenaria com piso de concreto, coberto com telhas de barro. Foi utilizado um termômetro de máxima e mínima, colocado no interior do galpão, para registro diário da temperatura. As temperaturas médias, mínima e máxima, verificadas no período foram, respectivamente, $21,0 \pm 1,36^{\circ} \mathrm{Ce} 26,7 \pm 2,46^{\circ} \mathrm{C}$.

Os tratamentos corresponderam a uma ração basal (Tabela 1) com 17,5\% de proteína bruta e $3.340 \mathrm{kcal}$ de ED, formulada de modo a exceder as recomendações nutricionais mínimas sugeridas pelo NRC (1998), suplementada com cinco níveis de LLisina-HCl 78,4\% (0,000; 0,127; 0,255; 0,3825; e $0,510 \%$ ) em substituição ao caulim, que resultou em rações experimentais com um total de 0,$80 ; 0,90$; 1,$00 ; 1,10 ;$ e $1,20 \%$ de lisina, fornecidas à vontade por todo período experimental.

As composições (em aminoácidos totais) dos ingredientes utilizados nas rações experimentais e da ração basal (em aminoácidos totais e digestíveis) encontram-se na Tabela 2. A digestibilidade dos aminoácidos sintéticos adicionados à ração foi considerada $100 \%$. As análises dos aminoácidos na ração basal, nos ingredientes (milho, farelo de soja e glúten de milho) e nas excretas foram realizadas no Laboratório da Guabi - Mogiana Alimentos S/A - Campinas, SP, utilizando-se analisador de aminoácidos HITACHI modelo $8500 \mathrm{~A}$.

As rações foram pesadas semanalmente, enquanto os animais foram pesados no início e no final do período experimental $(59,9 \pm 2,53 \mathrm{~kg})$, para determinação do consumo de ração e lisina, do ganho de peso e da conversão alimentar.

No final do experimento, foi coletado sangue e retirado o soro de um animal de cada unidade experimental, para determinação dos teores de uréia, conforme procedimentos descritos por Fontes et al. (2000).

O segundo animal de cada unidade experimental foi abatido, após jejum alimentar (24 horas) e hídrico (12 horas), por sangramento, sendo, posteriormente, depilados e eviscerados. As carcaças inteiras, incluindo cabeça e pés, foram pesadas e a metade esquerda foi triturada por $20 \mathrm{~min}$ em cutter comercial de $30 \mathrm{HP}$ e 1.775 revoluções por minuto. Após homogeneização, foram retiradas amostras, que foram conservadas a $-12^{\circ} \mathrm{C}$, sendo, posteriormente, pré-secas, pré- 
Tabela 1 - Composição centesimal da ração basal (\%)

Table 1 - Centesimal composition of the basal diet (\%)

\begin{tabular}{|c|c|}
\hline $\begin{array}{l}\text { Ingredientes } \\
\text { Ingredients }\end{array}$ & $\begin{array}{c}\text { Ração basal } \\
\text { Basal diet }\end{array}$ \\
\hline Milho & 68,83 \\
\hline \multicolumn{2}{|l|}{ Corn } \\
\hline Farelo de soja & 22,43 \\
\hline \multicolumn{2}{|l|}{ Soybean meal } \\
\hline Glúten de milho & 3,94 \\
\hline \multicolumn{2}{|l|}{ Corn gluten } \\
\hline Fosfato bicálcico & 1,54 \\
\hline \multicolumn{2}{|l|}{ Dicalcium phosphate } \\
\hline Calcário & 1,01 \\
\hline \multicolumn{2}{|l|}{ Limestone } \\
\hline Caulim & 1,50 \\
\hline Sal & 0,34 \\
\hline \multicolumn{2}{|l|}{ Salt } \\
\hline Premix mineral $^{1}$ & 0,05 \\
\hline \multicolumn{2}{|l|}{ Mineral mix } \\
\hline Premix vitamínico ${ }^{2}$ & 0,10 \\
\hline \multicolumn{2}{|l|}{ Vitamin mix } \\
\hline Antibiótico ${ }^{3}$ & 0,05 \\
\hline \multicolumn{2}{|l|}{ Antibiotic } \\
\hline Antioxidante 4 & 0,01 \\
\hline \multicolumn{2}{|l|}{ Antioxidant } \\
\hline DL-Metionina (99\%) & 0,068 \\
\hline \multicolumn{2}{|l|}{ DL-Methionine } \\
\hline L-Treonina $(98,5 \%)$ & 0,132 \\
\hline \multicolumn{2}{|l|}{ L-Threonine } \\
\hline TOTAL & 100,00 \\
\hline \multicolumn{2}{|l|}{ Composição calculada } \\
\hline \multicolumn{2}{|l|}{ Calculated composition } \\
\hline Energia digestível (kcal/kg) & 3.340 \\
\hline \multicolumn{2}{|l|}{ Digestible energy } \\
\hline Proteína bruta $(\%)$ & 17,5 \\
\hline \multicolumn{2}{|l|}{ Crude protein } \\
\hline Lisina total $(\%)$ & 0,80 \\
\hline \multicolumn{2}{|l|}{ Total lysine } \\
\hline Cálcio (\%) & 0,84 \\
\hline \multicolumn{2}{|l|}{ Calcium } \\
\hline Fósforo disponível (\%) & 0,38 \\
\hline Available phosphorus & \\
\hline
\end{tabular}

${ }^{1}$ Conteúdo por kg de ração (Content/kg of diet): Mn, 100 g; Fe, 100 g; Zn, 180 g; Cu, 40 g; Co, 1 g; I, 1,9 g; e veículo (vehicle) q.s.p. $1000 \mathrm{~g}$.

${ }^{2}$ Conteúdo/kg de ração (Conten/kg of diet): vit. A, 4.000.000 UI; vit. $\mathrm{D}_{3}, 800.000 \mathrm{UI}$; vit. E, 12.000 mg; vit $\mathrm{K}_{3}$, $4.000 \mathrm{mg}$; vit. $B_{1}, 1000 \mathrm{mg}$; vit. $B_{2}, 4.000 \mathrm{mg}$; vit. $B_{6}, 1600 \mathrm{mg}$; vit. $B_{12}, 21.000 \mathrm{mcg}$; ácido nicotínico (nicotinic acid), $25.000 \mathrm{mg}$; pantotenato de cálcio (panthotenate of calcium), $16.000 \mathrm{mg}$; Se, $200 \mathrm{mg}$; biotina (biotin), $40 \mathrm{mg}$; antioxidante (antioxidant), $30.000 \mathrm{mg}$; e veículo (vehicle) q.s.p., $1.000 \mathrm{~g}$.

3 Bacitracina de zinco (bacitracin of zinc).

${ }^{4} \mathrm{BHT}$ (Beta-hidroxi-tolueno) - Conteúdo (Content) - $100 \mathrm{~g} / \mathrm{kg}$. 
Tabela 2 - Composições dos ingredientes, em aminoácidos totais, e da ração basal, em aminoácidos totais e digestíveis (\%)

Table 2 - Composition of ingredients in total amino acid and composition of basal diet in total and digestible amino acid (\%)

\begin{tabular}{|c|c|c|c|c|c|c|}
\hline \multirow[t]{2}{*}{$\begin{array}{l}\text { Aminoácido } \\
\text { Amino acid }\end{array}$} & \multirow{2}{*}{$\begin{array}{l}\text { Milho } \\
\text { Corn } \\
\text { AAT }^{1} \\
\text { TAA }\end{array}$} & \multirow{2}{*}{$\begin{array}{c}\text { Farelo de soja } \\
\text { Soybean meal } \\
\text { AAT }^{1} \\
T A A\end{array}$} & \multirow{2}{*}{$\begin{array}{l}\text { Glúten de milho } \\
\text { Corn gluten } \\
\mathrm{AAT}^{1} \\
T A A\end{array}$} & \multicolumn{3}{|c|}{$\begin{array}{c}\text { Ração basal } \\
\text { Basal diet }\end{array}$} \\
\hline & & & & $\begin{array}{c}\mathrm{AAT}^{1} \\
T A A\end{array}$ & $\begin{array}{c}\mathrm{AADV}^{2} \\
R D A A\end{array}$ & $\begin{array}{r}\mathrm{AADA}^{3} \\
A D A A\end{array}$ \\
\hline $\begin{array}{l}\text { Lisina } \\
\text { Lysine }\end{array}$ & 0,22 & 2,71 & 1,03 & 0,800 & 0,691 & 0,651 \\
\hline $\begin{array}{l}\text { Metionina } \\
\text { Methionine }\end{array}$ & 0,13 & 0,52 & 1,30 & 0,324 & 0,279 & 0,257 \\
\hline $\begin{array}{l}\text { Met }+ \text { Cist } \\
M e t+C y s\end{array}$ & 0,29 & 1,17 & 2,26 & 0,618 & 0,519 & 0,488 \\
\hline $\begin{array}{l}\text { Treonina } \\
\text { Threonine }\end{array}$ & 0,24 & 1,44 & 1,56 & 0,681 & 0,586 & 0,554 \\
\hline $\begin{array}{l}\text { Isoleucina } \\
\text { Isoleucine }\end{array}$ & 0,25 & 1,64 & 2,00 & 0,619 & 0,535 & 0,498 \\
\hline $\begin{array}{l}\text { Arginina } \\
\text { Arginine }\end{array}$ & 0,35 & 3,58 & 2,00 & 1,123 & 1,089 & 1,058 \\
\hline $\begin{array}{l}\text { Valina } \\
\text { Valine }\end{array}$ & 0,34 & 1,69 & 2,27 & 0,703 & 0,595 & 0,549 \\
\hline $\begin{array}{l}\text { Triptofano } \\
\text { Tryptophan }\end{array}$ & 0,06 & 0,64 & 0,44 & 0,202 & 0,177 & - \\
\hline $\begin{array}{l}\text { Leucina } \\
\text { Leucine }\end{array}$ & 1,01 & 3,36 & 10,63 & 1,868 & 1,651 & 1,559 \\
\hline $\begin{array}{l}\text { Fenilalanina } \\
\text { Phenilalanine }\end{array}$ & 0,36 & 2,21 & 3,81 & 0,894 & 0,762 & 0,723 \\
\hline $\begin{array}{l}\text { Histidina } \\
\text { Hystidine }\end{array}$ & 0,22 & 1,14 & 1,26 & 0,457 & 0,444 & 0,403 \\
\hline $\begin{array}{l}\text { Tirosina } \\
\text { Tyrosine }\end{array}$ & 0,31 & 1,48 & 2,99 & 0,663 & 0,598 & 0,560 \\
\hline
\end{tabular}

desengorduradas, moídas e acondicionadas, conforme descrito por Fontes et al. (2000), para análises de umidade, proteína bruta e gordura, realizadas de acordo com Silva (1990).

Um grupo adicional de cinco animais, da mesma linhagem, com peso médio de $29,7 \pm 1,09 \mathrm{~kg}$, foi abatido para determinação da composição da carcaça dos suínos no início do experimento.

As taxas de deposição de proteína e gordura nas carcaças foram calculadas comparando-se as composições das carcaças dos animais no início e no fim do período experimental.

As variáveis de desempenho, os níveis de uréia no soro dos animais, a composição de carcaça e as taxas de deposição de proteína e gordura nas carcaças foram submetidos à análise de variância, utilizando-se o Sistema de Análises Estatísticas e Genéticas - SAEG (1997).

A estimativa de exigência de lisina foi estabelecida por meio de modelos de regressão lineare/ou quadrático.
Para determinação da exigência de lisina digestível, foi considerado o coeficiente de digestibilidade verdadeira da lisina obtido por Fontes et al. (2000).

\section{Resultados e Discussão}

Os resultados de ganho de peso, conversão alimentar, consumos de ração e de lisina e do teor de uréia no soro sangüíneo de leitoas dos 30 a $60 \mathrm{~kg}$ encontram-se na Tabela 3.

Não se observou efeito $(\mathrm{P}>0,10)$ dos tratamentos sobre o ganho de peso médio diário (GPD). Os resultados são semelhantes aos obtidos por Donzele et al. (1994) e Souza (1997), que não observaram efeito dos níveis de lisina sobre o ganho de peso de leitoas dos 30 aos $60 \mathrm{~kg}$, porém diferem dos relatos de Martinez \& Knabe (1990), que observaram efeitos linear e quadrático dos tratamentos sobre o GPD de suínos de 21 a $49 \mathrm{~kg}$. 
Tabela 3 - Desempenho, consumo de lisina e nível de uréia no soro sangüíneo de leitoas dos 30 aos $60 \mathrm{~kg}$, em função do nível de lisina da ração

Table 3 - Performance, lysine intake and urea level on blood serum of gilts from 30 to $60 \mathrm{~kg}$, in function of the lysine level of diet

\begin{tabular}{|c|c|c|c|c|c|c|}
\hline \multirow[t]{2}{*}{$\begin{array}{l}\text { Parâmetro } \\
\text { Parameter }\end{array}$} & \multicolumn{5}{|c|}{$\begin{array}{c}\text { Nível de lisina total na ração(\%) } \\
\text { Total lysine level of diet }(\%)\end{array}$} & \multirow[t]{2}{*}{$\mathrm{CV}(\%)$} \\
\hline & 0,80 & 0,90 & 1,00 & 1,10 & 1,20 & \\
\hline $\begin{array}{l}\text { Ganho de peso }(\mathrm{g} / \mathrm{dia})^{1} \\
\text { Weight gain }(\mathrm{g} / \text { day })\end{array}$ & 848 & 941 & 922 & 927 & 912 & 6,90 \\
\hline $\begin{array}{l}\text { Consumo ração }(\mathrm{g} / \mathrm{dia})^{2} \\
\text { Feed intake (g/day) }\end{array}$ & 1979 & 2108 & 1959 & 1828 & 1884 & 6,59 \\
\hline $\begin{array}{l}\text { Conversão alimentar } \\
\text { Feed:gain ratio }\end{array}$ & 2,24 & 2,12 & 1,97 & 2,07 & 5,13 & \\
\hline $\begin{array}{l}\text { Consumo lisina }(\mathrm{g} / \mathrm{dia})^{4} \\
\text { Lysine intake }(\mathrm{g} / \text { day })\end{array}$ & 15,83 & 18,97 & 19,59 & 20,11 & 22,61 & 6,66 \\
\hline $\begin{array}{l}\text { Uréia }(\mathrm{mg} / \mathrm{dL}) \\
\text { Urea }\end{array}$ & 34,52 & 34,12 & 36,24 & 34,80 & 35,14 & 13,57 \\
\hline
\end{tabular}

O consumo de ração diário $(\mathrm{CRD})$ reduziu $(\mathrm{P}<0,03)$ de forma linear em função dos níveis de lisina da ração, corroborando os estudos de Martinez \& Knabe (1990), que verificaram efeitos linear e quadrático dos níveis de lisina sobre o CRD de suínos de 21 a 49 kg, mas diferindo dos achados de Friesen et al. (1994), que, avaliando níveis de lisina $(0,68$ a $1,25 \%)$ para leitoas com alto potencial genético para deposição de carne magra na carcaça, não observaram efeito dos tratamentos sobre o CRD, em animais de 36 a $54 \mathrm{~kg}$, e de Donzele et al. (1994), que também não constataram efeito dos níveis de lisina $(0,63$ a $1,03 \%)$ sobre o CRD de leitoas dos 30 aos $60 \mathrm{~kg}$.

Observou-se efeito quadrático $(\mathrm{P}<0,08)$ dos níveis de lisina sobre a conversão alimentar (CA), que melhorou até o nível de 1,16\% (0,347\%/Mcal de ED) (Figura 1), correspondente a um consumo estimado de lisina total de 21,77 g/dia (3,47 g/Mcal de ED) ou de $1,05 \%(0,315 \% /$ Mcal de ED) de lisina digestível verdadeira, correspondente a um consumo de lisina digestível de 19,72 g/dia (3,15g /Mcal de ED).

A relação lisina:proteína total, no nível de 1,16\%, que proporcionou melhores resultados de CA, correspondeu a $6,6 \%$, estando coerente com o valor de 6,5\% observado por Yen et al. (1986) e Donzele et al. (1994). Do mesmo modo, Henry \& Séve (1993), avaliando o balanço aminoacídico de ração para suínos em crescimento, verificaram que a relação ideal entre lisina e proteína total situou-se entre 6,5 e $6,8 \%$. Nesse mesmo nível de lisina total $(1,16 \%)$, a relação entre os aminoácidos treonina, triptofano e

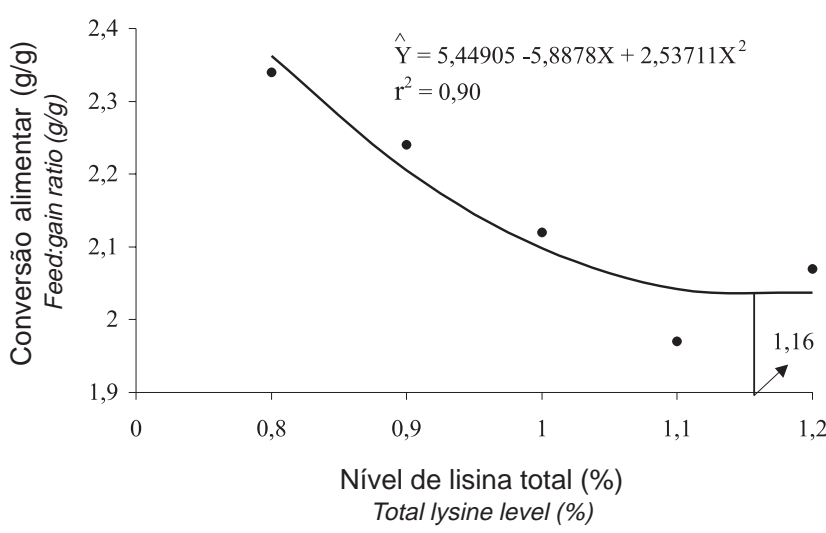

Figura 1 - Efeito do nível de lisina sobre a conversão alimentar de leitoas dos 30 aos $60 \mathrm{~kg}$.

Figure 1 - Effect of lysine level of diet on feed:gain ratio of gilts from 30 to $60 \mathrm{~kg}$.

metionina+cistina e a lisina foi de 59; 17,5; e 53\%, respectivamente. Estes resultados são semelhantes aos obtidos por Donzele et al. (1994), de 60, 18 e 54\%, para leitoas dos 30 aos $60 \mathrm{~kg}$, e estão abaixo daqueles referenciados pelo NRC (1998), de 64, 18 e $57 \%$, para suínos dos 20 aos $50 \mathrm{~kg}$.

O nível de lisina total $(1,16 \%)$ que proporcionou o melhor resultado de conversão alimentar foi superior aos obtidos por Yen et al. (1986), Donzele et al. (1994) e Souza (1997), de 1,08\%; 0,91\%; e 0,75\%, respectivamente.

No entanto, considerando os dados de consumo diário de lisina no nível que proporcionou o melhor 
resultado de CA, os resultados deste estudo são coerentes com os relatados por Friesen et al. (1994), que sugerem que leitoas com alto potencial genético para deposição de carne magra, dos 34 aos $72 \mathrm{~kg}$, requerem consumo de lisina total e digestível de 22 e $18 \mathrm{~g} /$ dia, respectivamente.

O consumo de lisina diário elevou-se de modo linear $(\mathrm{P}<0,01)$ com o aumento dos níveis de lisina da ração, o que está de acordo com outros trabalhos (Friesen et al., 1994; Fontes et al., 1997; Souza, 1997; Moretto et al., 2000).

Não se observou efeito $(\mathrm{P}>0,10)$ dos níveis de lisina sobre o teor de uréia no soro sangüíneo dos animais, evidenciando que, nas condições do presente experimento, este parâmetro não foi efetivo na determinação da exigência de lisina. Este resultado contrasta com aqueles obtidos por Yen et al. (1986) e Coma et al. (1995), que concluíram que o teor de uréia plasmática (TUP) foi uma variável adequada para determinar os requerimentos de lisina de suínos. Considerando-se que este parâmetro normalmente apresenta alto coeficiente de variação, deduz-se que o número de repetições adotados para avaliar essa variável tenha sido baixo, o que pode ter contribuído para a falta de consistência destes resultados. Assim como em leitoas na fase inicial, observou-se que o padrão de consumo de ração dos animais após o período de jejum não foi uniforme, constatando-se variação considerável entre os animais das diferentes unidades experimentais, o que também pode ter influenciado estes resultados. É possível que o período de jejum de 24 horas seja inadequado para animais nessa faixa de peso.

Os resultados da composição química e das taxas de deposição de proteína e gordura na carcaça de leitoas dos 30 aos $60 \mathrm{~kg}$ são apresentados na Tabela 4.

Tabela 4 - Composição de carcaça e taxas de deposição de gordura e proteína na carcaça de leitoas dos 30 aos 60 kg, em função do nível de lisina da ração

Table 4 - Carcass composition, fat and protein deposition rate in carcass of gilts from 30 and $60 \mathrm{~kg}$, in function of the lysine level of diet

\begin{tabular}{|c|c|c|c|c|c|c|}
\hline \multirow{3}{*}{$\begin{array}{l}\text { Parâmetro } \\
\text { Parameter }\end{array}$} & \multirow{2}{*}{\multicolumn{5}{|c|}{$\begin{array}{c}\text { Nível de lisina total na ração }(\%) \\
\text { Total lysine level of diet }\end{array}$}} & \multirow[t]{3}{*}{$\mathrm{CV}(\%)$} \\
\hline & & & & & & \\
\hline & 0,80 & 0,90 & 1,00 & 1,10 & 1,20 & \\
\hline \multicolumn{7}{|c|}{ Composição de carcaça (\%) } \\
\hline \multicolumn{7}{|c|}{ Carcass composition } \\
\hline Água & 60,73 & 61,99 & 63,15 & 64,00 & 62,95 & 3,04 \\
\hline \multicolumn{7}{|l|}{ Water } \\
\hline Proteína & 16,90 & 17,46 & 17,85 & 17,60 & 17,44 & 5,32 \\
\hline \multicolumn{7}{|l|}{ Protein } \\
\hline Gordura $^{1}$ & 17,66 & 16,68 & 15,02 & 14,32 & 15,43 & 5,12 \\
\hline \multicolumn{7}{|l|}{ Fat } \\
\hline \multicolumn{7}{|c|}{ Taxa de deposição na carcaça (g/dia) } \\
\hline \multicolumn{7}{|c|}{ Carcass deposition rate (g/day) } \\
\hline Proteína ${ }^{2}$ & 140,24 & 167,26 & 170,96 & 166,93 & 161,63 & 11,45 \\
\hline \multicolumn{7}{|l|}{ Protein } \\
\hline Gordura $^{3}$ & 181,12 & 178,39 & 145,39 & 133,46 & 151,07 & 13,20 \\
\hline \multicolumn{7}{|l|}{ Fat } \\
\hline \multirow{2}{*}{\multicolumn{7}{|c|}{$\begin{array}{l}\text { Energia retida na carcaça }(\mathrm{kcal} / \mathrm{dia}) \\
\text { Retained energy in carcass }(\mathrm{kcal} / \text { dav })^{4}\end{array}$}} \\
\hline \multicolumn{4}{|c|}{ Retained energy in carcass $(k c a l / d a y)^{4}$} & & & \\
\hline Total & 2487 & 2614 & 2324 & 2189 & 2325 & \\
\hline \multicolumn{7}{|l|}{ Total } \\
\hline Proteína (\%) & 31,56 & 35,84 & 41,18 & 42,71 & 38,92 & \\
\hline \multicolumn{7}{|l|}{ Protein } \\
\hline Gordura(\%) & 68,44 & 64,15 & 58,82 & 57,29 & 61,07 & \\
\hline Fat & & & & & & \\
\hline
\end{tabular}

${ }^{1}$ Efeito linear $(\mathrm{P}<0,03) \quad-\mathrm{Y}=60,2702+3,74115 \mathrm{X}\left(\mathrm{r}^{2}=0,67\right)$ (Linear effect, $\left.P<.03\right)$.

2 Efeito quadrático $(P<0,01)-\mathrm{Y}=58,6198-80,240 \mathrm{X}+36,7106 \mathrm{X}^{2}\left(\mathrm{r}^{2}=0,91\right)$ (Quadratic effect, $\left.P<.02\right)$

3 Efeito quadrático $(\mathrm{P}<0,01)-\mathrm{Y}=-387,724+1076,5 \mathrm{X}-517,028 \mathrm{X}^{2}\left(\mathrm{r}^{2}=0,92\right)$ (Quadratic effect, $\left.P<.01\right)$

4 Efeito quadrático $(P<0,02)-\mathrm{Y}=695,098-987,031 \mathrm{X}+441,0 \mathrm{X}^{2}\left(\mathrm{r}^{2}=0,78\right)$ (Quadratic effect, $\left.P<.02\right)$.

${ }^{5}$ Para o cálculo da energia retida na carcaça, foram considerados os valores de energia de 5,6 e 9,4 kcal/kg para proteína e gordura, respectivamente (The values of energy of 5.6 and $9.4 \mathrm{kcal} / \mathrm{kg}$ for protein and fat were used to calculate, respectively, retained energy in carcass). 
Não se observou efeito $(\mathrm{P}>0,10)$ dos tratamentos sobre a porcentagem de proteína na carcaça, entretanto, constatou-se que a porcentagem de água aumentou de maneira linear $(\mathrm{P}<0,03)$, com efeito quadrático $(\mathrm{P}<0,01)$ sobre a porcentagem de gordura (Figura 2$)$, que diminuiu até o valor correspondente a $14,32 \%$ no nível de $1,09 \%$ de lisina $(0,326 \%$ /Mcal de ED) ou de $0,98 \%$ de lisina digestível (0,293\%/Mcal de ED).

No tratamento correspondente ao nível de $1,10 \%$ de lisina na ração, as porcentagens de proteína e água na carcaça atingiram valores de 17,6 e $64 \%$, respectivamente, enquanto a porcentagem mínima de gordura foi de $14,32 \%$. Estes valores, com exceção da gordura, estão coerentes com os obtidos por Friesen et al. (1994), que observaram que o conteúdo máximo de proteína e água foi de 18,1 e $64,5 \%$, respectivamente, e o conteúdo mínimo de gordura, de $11,4 \%$ na carcaça de leitoas dos 34 aos $72 \mathrm{~kg}$.

Close (1994), estudando as alterações de composição de carcaça de genótipos modernos de suínos com base em revisão de literatura, relatou que a porcentagem de proteína na carcaça não variou substancialmente entre os grupos genéticos. Isso sugere que o melhoramento genético tem aumentado as taxas de deposição de proteína, sem, no entanto, alterar significativamente a concentração de proteína na carcaça. $\mathrm{O}$ fato da porcentagem de gordura corporal nos genótipos melhorados ter diminuído de $25-30 \%$ para 15-20\% indica que o conteúdo de água pode estar mais elevado em relação aos animais de menor mérito genético. Estudos sugerem que o conteúdo de água

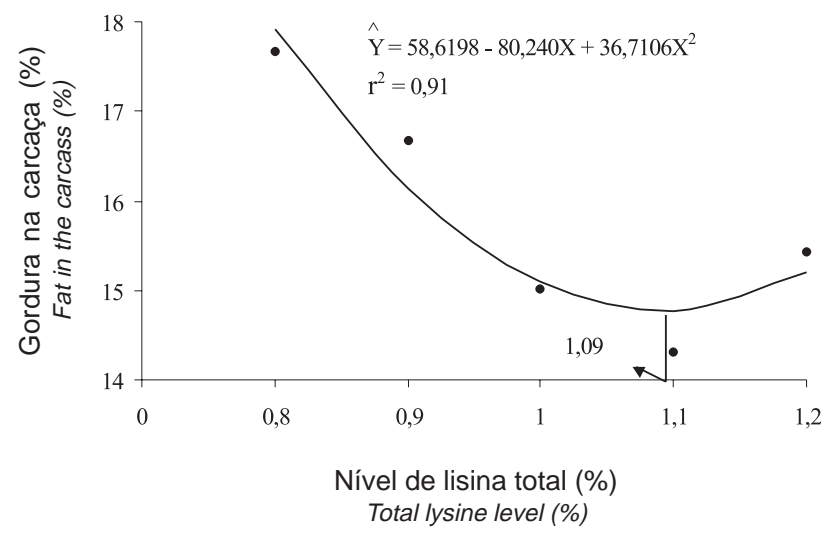

Figura 2 - Efeito do nível de lisina sobre a porcentagem de gordura na carcaça de leitoas aos $60 \mathrm{~kg}$.

Figure 2 - Effect of lysine level of diet on fat content in carcass of gilts at $60 \mathrm{~kg}$. corporal dos genótipos melhorados varia de 63 a $66 \%$ (Friesen et al., 1994; Bikker et al., 1994), sendo superiores às estimativas de 53 a 58\%, respectivamente, do ARC (1981) e de Fontes et al. (1996), obtidos com suínos puros da raça Landrace. De fato, os resultados deste trabalho confirmam estas observações.

Houve efeito $(\mathrm{P}<0,01)$ quadrático dos níveis de lisina sobre a taxa de deposição de proteína (Figura 3), que aumentou até o nível de 1,04\% (0,311\%/Mcal de ED) ou $0,93 \%(0,278 \% / \mathrm{Mcal}$ de ED) de lisina digestível, correspondente a um consumo estimado de lisina total e digestível de $20 \mathrm{~g} / \mathrm{dia}$ (3,0 g/Mcal de ED) e $17,91 \mathrm{~g} /$ dia $(2,77 \mathrm{~g} / \mathrm{Mcal}$ de ED) e à taxa de deposição de proteína estimada de 172,6 g/dia. Este valor, referente à taxa de deposição de proteína, está de acordo com aquele de $171 \mathrm{~g} /$ dia estimado por Close (1994), para suínos de genótipos superiores aos $40 \mathrm{~kg}$ de peso.

Os resultados deste estudo estão de acordo com os obtidos por Campbell \& Taverner (1988), que sugerem que leitoas de alto potencial genético requerem 20 g/dia de lisina para otimizar a deposição de proteína na carcaça. Do mesmo modo, são semelhantes aos dados de Lawrence et al. (1994), que, avaliando diferentes relações entre lisina e energia digestível (2,5 a 4,0 g/Mcal de ED) para suínos com médio potencial genético para deposição de carne magra na carcaça, dos 21 aos $50 \mathrm{~kg}$, estimaram em 3,0 g/Mcal de ED o requerimento de lisina, para máxima deposição de proteína e carne magra na carcaça, assim como para retenção de nitrogênio.

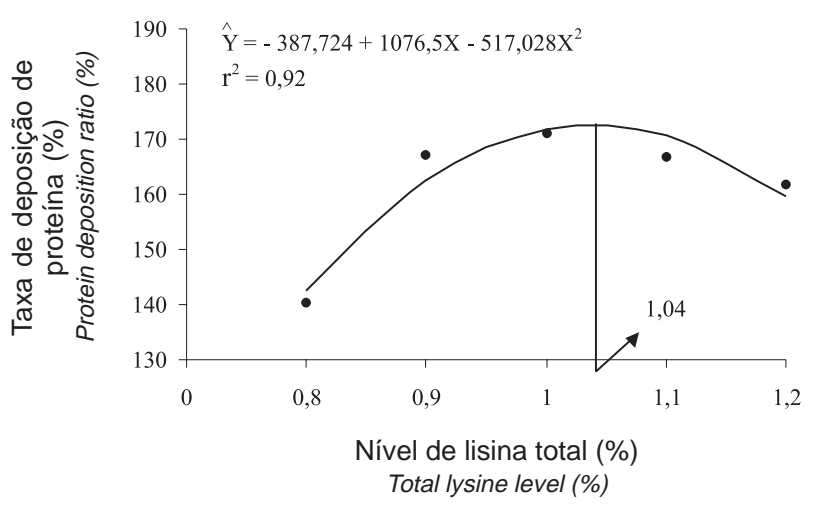

Figura 3 - Efeito do nível de lisina sobre a taxa de deposição de proteína na carcaça de leitoas dos 30 aos $60 \mathrm{~kg}$.

Figure 3 - Effect of lysine level of diet on protein deposition rate in carcass of gilts from 30 to $60 \mathrm{~kg}$. 
Constatou-se efeito quadrático $(\mathrm{P}<0,02)$ dos tratamentos sobre a taxa de deposição de gordura (Figura 4), que diminuiu até o nível de $1,12 \%$ de lisina $(0,335 \%)$ Mcal de ED), correspondente a um consumo de lisina de 21,18 g/dia (3,24 g/Mcal de ED). Resultados semelhantes foram obtidos por Chiba et al. (1991), que observaram menor taxa de deposição de gordura no nível de lisina de 3,4 g/Mcal de ED. Por outro lado, Friesen et al. (1994) observaram que a taxa de deposição de gordura foi mínima no nível de $1,00 \%$ de lisina na ração $(0,84 \%$ de lisina digestível).

Os resultados deste estudo indicam que, de modo geral, a porcentagem e as taxas de deposição de gordura na carcaça foram influenciadas de maneira inversa às de proteína, em função do nível de lisina da ração. Estas observações são semelhantes às obtidas por Friesen et al. (1994) e Bikker et al. (1994).

O nível de $1,16 \%$ de lisina total, que proporcionou os melhores resultados de CA, e o nível de 1,04\%, que proporcionou os melhores resultados de taxa de deposição de proteína na carcaça, estão acima dos encontrados em diferentes trabalhos (Chiba et al., 1991; Donzele et al., 1994; Souza, 1997) e da recomendação do NRC (1998), de 0,95 e 0,83\% como os requerimentos de lisina total e digestível verdadeira, respectivamente, em ração contendo $3,4 \mathrm{Mcal}$ de ED $/ \mathrm{kg}$ e $18 \%$ de proteína bruta, para suínos dos 20 aos $50 \mathrm{~kg}$.

Por outro lado, os resultados deste experimento estão de acordo com os obtidos por Rao \& Mccraken (1990), que estimaram o requerimento de lisina em

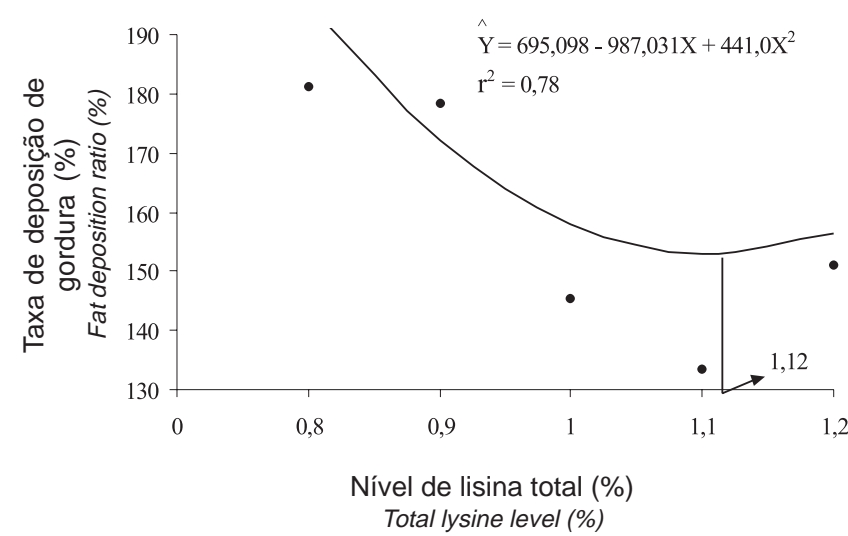

Figura 4 - Efeito do nível de lisina sobre a taxa de deposição de gordura na carcaça de leitoas dos 30 aos $60 \mathrm{~kg}$.

Figure 4 - Effect of lysine level of diet on fat deposition rate in carcass of gilts from 30 to $60 \mathrm{~kg}$.
3,35 g/Mcal de ED, correspondente a 1,13\%, e consumo de 21,2 g/dia, para machos inteiros com alto potencial genético para deposição de carne magra na carcaça, dos 33 aos $55 \mathrm{~kg}$ de peso, e aos relatados por Friesen et al. (1994), que sugerem que os consumos de lisina total e digestível de 22 e $18 \mathrm{~g} / \mathrm{dia}$, respectivamente, resultam em máxima eficiência alimentar e deposição de proteína na carcaça para leitoas em crescimento.

\section{Conclusões}

Leitoas selecionadas geneticamente para deposição de carne magra na carcaça, dos 30 aos $60 \mathrm{~kg}$, exigem $1,16 \%$ de lisina total ou $1,05 \%$ de lisina digestível verdadeira, para melhor desempenho, correspondendo a um consumo estimado de lisina total e digestível de $21,77 \%$ e $19,72 \mathrm{~g} /$ dia, respectivamente. O nível de $1,04 \%$ de lisina total ou $0,93 \%$ de lisina digestível verdadeira proporciona a melhor taxa de deposição de proteína na carcaça.

\section{Agradecimento}

À Agroceres Nutrição Animal e Agroceres - Pic, pela cooperação.

\section{Literatura Citada}

AGRICULTURAL RESEARCH COUNCIL - ARC. The nutrient requirements of the pig. Sloug: Commonwealth Agricultural Bureaux, 1981. 307p.

BIKKER, P.; VERSTEGEN, M.W.A.; CAMPBELL, R.G. et al. Digestible lysine requirements of gilts with high genetic potential for lean gain, in relation to the level of energy intake. Journal Animal Science, v.72, n.7, p.1744-1753, 1994.

BIKKER, P.; BOSCH, M. Nutrient requirements of pigs with high genetic potential for lean gain. In: SIMPÓSIO INTERNACIONAL SOBRE EXIGÊNCIAS NUTRICIONAIS DE AVES E SUÍNOS, 1996, Viçosa, MG. Anais...Viçosa, MG: Universidade Federal de Viçosa, 1996.

CAMPBELL, R.G.; TAVERNER, M.R. Genotype and sex effects on the relationship between energy intake and protein deposition in growing pigs. Journal of Animal Science, v.66, n.3, p.676-686, 1988.

CHIBA, L.I.; LEWIS, A.J.; PEO JR., E.R. Amino acid and energy interrelationships in pigs weighing 20 to 50 kilograms: I. Rate e efficiency of weight gain. Journal Animal Science, v.69, n.2, p.694-707, 1991.

CLOSE, W.H. Feeding new genotypes: establishing amino acid/ energy requirement. In: COLE, D.J.A.; WISEMAN, J.; VARLEY, M.A. (Eds.) Principles of pig science. 1.ed. Loughborough: Nottigham University Press, 1994. p.123-140.

COMA, J.; CARRION, D.; ZIMMERMAN, D.R. Use of plasma urea nitrogen as a rapid response criterion to determine the 
lysine requirement of pigs. Journal of Animal Science, v.73, n.2, p.472-481, 1995.

DONZELE, J.L.; FREITAS, R.T.F.; OLIVEIRA, R.F.M. et al. Níveis de lisina para leitoas de 30 a $60 \mathrm{~kg}$ de peso vivo. Revista Brasileira de Zootecnia, v.24, n.6, p.967-973, 1994.

FÁVERO, J.A. Melhoria de carcaça de suínos: importância dos processos de tipificação e abate de machos inteiros. In: SIMPÓSIO SOBRE NUTRIÇÃO E MANEJO DE AVES E SUÍNOS. Anais... Campinas: Colégio Brasileiro de Nutrição Animal, 2000. p135-151.

FONTES, D.O.; DONZELE, J.L.; ROSTAGNO, H.S. et al. Níveis de energia digestível para leitoas dos 30 aos $60 \mathrm{~kg}$. Revista Brasileira de Zootecnia, v.25, n.6, p.1124-1138, 1996.

FONTES, D.O.; DONZELE, J.L.; CONHALATO, G.S. Níveis de lisina para leitoas com alto potencial genético para deposição de carne magra, dos 15 aos $30 \mathrm{~kg}$. In: REUNIÃO ANUAL DA SOCIEDADE BRASILEIRA DE ZOOTECNIA, 34.,1997, Juiz de Fora, MG. Anais... Juiz de Fora: Sociedade Brasileira de Zootecnia, 1997. p.78-80.

FONTES, D.O.; DONZELE, J.L.; FERREIRA, A.S. et. al. Níveis de lisina para leitoas selecionadas geneticamente para deposição de carne magra , dos 60 aos $95 \mathrm{~kg}$. Revista Brasileira de Zootecnia, n.29, v.3, p.784-793, 2000.

FRIESEN, K.G.; NELSSEN, J.L.; GOODBAND, R.D. et al. Influence of dietary lysine on growth and carcass composition of high-lean-growth gilts fed from 34 to 72 kilograms. Journal Animal Science, v.72, n.7, p.1761-1770, 1994.

HENRY, Y.; SÉVE, B. Feed intake and dietary amino acid balance in growing pigs with special reference to lysine, tryptophan and threonine. Pig News and Information, v.14, n.1, p.35-43, 1993.

LAWRENCE, B.V.; ADEOLA, O.; CLINE, T.R. Nitrogen utilization and lean growth performance of 20 to 50 kilogram pigs fed diets balanced for lysine:energy ratio. Journal Animal Science, v.72, n.11, p.2887-2895, 1994.

MARTINEZ, G.M.; KNABE, D.A. Digestible lysine requirement of starter and grower pigs. Journal of Animal Science, v.68, n.9, p.2748-2755, 1990.

MORETTO, V.; DONZELE, J.L.; OLIVEIRA, R.F.M. et al. Níveis de lisina dietética para suínos da raça Landrace dos 15 aos 30 kg. Revista Brasileira de Zootecnia, v.29, n.3, p.803-809, 2000.
NATIONAL RESEARCH COUNCIL - NRC. Committee on Animal Nutrition. Subcommittee of Swine Nutrition. Washington. Nutrient requirements of swine. 10.ed. Washington: National Academic of Sciences, 1998. 189p.

NUGENT, R.A.; CHEWNING, J.J.; SMITH, P.A. Genotype by daily lysine intake interaction effects for growth and carcass traits for two genetic lines of swine. Journal of Animal Science, v.72 (suppl. 1), p.219 (Abstr.), 1994.

RAO, D.S.; McCRACKEN, K.J. Protein requirements of boars of high genetic potential for lean growth. Animal Production, v.51, part.1, p.179-187, 1990 .

SILVA, D.J. Análise de alimentos: métodos químicos e biológicos. 2.ed. Viçosa, MG: Universidade Federal de Viçosa, 1990. 166p.

SOUZA, A.M. Exigências nutricionais de lisina para suínos mestiços, de 15 a $95 \mathrm{~kg}$ de peso. Viçosa, MG: Universidade Federal de Viçosa, 1997. 81p. Dissertação (Mestrado em Zootecnia) - Universidade Federal de Viçosa, 1997.

STAHLY, T.S.; CROMWELL, G.L.; TERHUNE, D. Responses of high, medium and low lean growth genotypes to dietary amino acid regimen. Journal of Animal Science, v.69 (suppl. 1), p.364 (Abstr.), 1991.

UNIVERSIDADE FEDERAL DE VIÇOSA - UFV. SAEG Sistemas de Análises Estatísticas e Genéticas. Versão 7.1. Viçosa, MG: 1997. 150p. (Manual do usuário)

YEN, H.T.; COLE, D.J.A.; LEWIS, D. Amino acid requirements of growing pigs. 7. The response of pigs from 25 to $35 \mathrm{~kg}$ live weight to dietary ideal protein. Animal Production, v.43, part.1, p.141-154, 1986. 